\title{
LA EVOCACIÓN MUSICAL DEL MEDIEVO: CANCIÓN NARRATIVA, DRAMA Y CINE «MEDIEVAL» EN INGLÉS
}

\author{
Julio Rubén Valdés Miyares \\ Universidad de Oviedo
}

\section{Resumen}

Durante la Edad Media se consolidó una poderosa conjunción de música y narrativa oral en la que ambas se reforzaban para producir una serie de efectos emocionales. También en el teatro la música sirvió a efectos dramáticos, especialmente para evocar lo sagrado en el drama de origen litúrgico, o bien otros tiempos y lugares como el bosque de Arden en el de Shakespeare, basado en ideas medievales del bosque como el de Robin Hood. En la tradición de la balada popular continúa más allá de la Edad Media la asociación entre relato y melodía, hasta que en el siglo XIX, coincidiendo con el auge de la novela, se desligan, para volver a unirse definitivamente, junto con las imágenes, en la era del cine. Pero la música del cine de tema medieval apenas tiene que ver con aquella música medieval, salvo en la nostalgia por otro tiempo perdido en un mítico pasado.

PALABRAS ClAVE: medievalismo, música y narración, cultura popular, baladas, cine y música.

EVOKING THE MIDDLE AGES THROUGH MUSIC: "MEDIEVAL"

NARRATIVE SONG, DRAMA AND FILM IN ENGLISH

\section{Abstract}

During the Middle Ages music and oral narrative came together in a forceful conjunction where they jointly produced sets of emotional effects. Music also served dramatic purposes in theatre, particularly to evoke the sacred in plays based on liturgical drama, or else to conjure other times and places such as the Forest of Arden in Shakespeare's As You Like It, based on the medieval Robin Hood forest. It is in the popular ballad tradition that the link of narrative and melody continues beyond the Middle Ages, until the $19^{\text {th }}$ century milieu, coinciding with the hegemony of the novel, when they tend to come apart. Music and text, along with the visual, definitely meet again in the age of cinema, however the music in films of medieval subjects hardly relates to actual medieval music, save for the nostalgia of a time lost in the mythic past.

KEYWORDS: medievalism, music and narrative, popular culture, ballads, drama, film music. 


\section{INTRODUCCIÓN}

El objeto del presente estudio es trazar una amplia comparativa, entre distintos géneros y épocas, sobre el poder de evocación de la música en el teatro medieval, las baladas en inglés y el cine de ambientación medieval. El enfoque crítico adoptado es el del medievalismo, que analiza la recreación y el estudio de lo que en los distintos periodos se ha considerado el mundo medieval ${ }^{1}$. Dos formas secuenciales de arte, la música y la narrativa literaria, fundidas luego con una tercera, el cine, contrastan en una sinergia que parece haber existido desde siempre, como si ambas artes hubiesen nacido al unísono.

Prácticamente desde que se tiene noticia de la literatura como arte, su representación pública ha estado asociada con la música. Los scops, o poetas tradicionales anglosajones, al igual que sus antecesores los vates y los bardos, acompañaban sus historias con la música del arpa. En el primer gran poema épico inglés, Beowulf, leemos en el antiguo inglés cómo "cada día, tañendo el arpa, y en la canción clara del poeta, se contaba con maestría el principio del hombre...». ${ }^{2}$ No es de extrañar que los primeros grandes poemas épicos europeos -el de Roland, el de Mio Cid, el de los Nibelungos-, se llamaran chançon, cantar o Lied, términos relacionados con la canción, como también lo está el de lay que aparece en la literatura inglesa ${ }^{3}$.

${ }^{1}$ La definición de «medievalismo» que nos atañe se refiere tanto al sistema de creencias y prácticas propias de la Edad Media como a la devoción hacia los elementos de esa época, que se ha venido expresando en periodos posteriores en campos tan diversos como la arquitectura, literatura, arte, música, filosofía, y en diversas formas de cultura popular, incluyendo el cine, así como los estudios académicos sobre todas estas disciplinas. Véase «Medievalism» en J. Simpson y E. Weiner (eds.), The Oxford English Dictionary. Oxford, Oxford University Press (2. ${ }^{a}$ edición), 1989, vol. Ix. La Sociedad Internacional para el Estudio del Medievalismo, por su parte, lo define algo más concretamente: "Medievalism is the study of responses to the Middle Ages at all periods since a sense of the mediaeval began to develop. Such responses include, but are not restricted to, the activities of scholars, historians and philologists in rediscovering medieval materials; the ways in which such materials were and are used by political groups intent on self-definition or self-legitimation; and artistic creations, whether literary, visual or musical, based on whatever has been or is thought to have been recovered from the medieval centuries. The Middle Ages remain present, moreover, in the modern consciousness, both through scholarship and through popular media such as film, video games, poster art, TV series and comic strips, and these media are also a legitimate object of study, if often intertwined with more traditionally scholarly topics». Recuperado de http://www.medievalism.net/.

2 «... dogora... / hludne in healle; pær wæs hearpan sweg, / swutol sang scopes. Sægde se pe cupe / frumsceaft fira feorran reccan». S. Heaney (ed.), Beowulf. Londres, Faber and Faber, 1999, p. 8, versos 89-91. Traducción propia. La asociación entre el poeta y el arpa tiene una larga historia en la poesía narrativa inglesa que se verifica de manera crucial en la tradición de las baladas: véase R. Valdés Miyares, «The Ballad and the Harp: an approach to the history of English narrative song of medieval tradition", en P. Fernández Nistal y J.M. Bravo Gozalo (eds.), Proceedings of the VI ${ }^{\text {th }}$ International Conference of the Spanish Society for Medieval English Language and Literature, Valladolid, Secretariado de Publicaciones de la Universidad, 1995, pp. 361-368.

${ }^{3}$ El término lay, que designa en la literatura inglesa una balada o poema narrativo breve para ser cantado, o bien simplemente una canción o melodía (https://www.collinsdictionary.com/ dictionary/english/lay), no se conoce hasta el siglo xıII, cuando aparece asociado con la Bretaña 
Tras la Edad Media el maridaje entre la narrativa y la música tuvo una importante pervivencia en géneros tales como los romances castellanos y su equivalente en lengua inglesa, las baladas, y también, en cierta medida, en el teatro. Cuando a principios del siglo xx la novela empieza a desplazar como género popular a los anteriores, surge el cine, donde renace con singular vigor la narrativa (a menudo tanto o más visual que verbal) unida a canciones o música. Donde se ve con la mayor naturalidad cuánto tiene de medieval ese contar con música es en aquellas películas que precisamente quieren narrar historias medievales.

\section{NARRACIÓN Y EMOCIÓN}

Siempre ha habido una asociación entre las emociones suscitadas por la música y el sentido dramático de la narración que la acompaña. La proximidad sin duda se debe a que tanto la narración dramática, particularmente la poesía, como la música suelen apelar a las emociones, y juntas se refuerzan mutuamente, o se convierten una en contrapunto de la otra. En la comunicación verbal Jacobson identificó una función poética que se centra en el mensaje comunicado, en principio diferenciada de la función emotiva, que se centra en el sujeto comunicante, pero en la práctica ambas funciones están íntimamente ligadas en géneros como la lírica ${ }^{4}$, un género a su vez muy relacionado con la música 5 . Por su parte, en musicología ya existen amplios estudios sobre la música y las emociones. Entre las emociones positivas provocadas por la música se mencionan la felicidad o alegría, el disfrute o deleite (o dulzura y belleza), y la paz o armonía; entre los negativos, la melancolía, infelicidad o tristeza, el cansancio, agotamiento o "vacío», y la confusión, tensión o preocupación; además, entre las experiencias transcendentales relacionadas con la música, cabe destacar la religiosas por su indudable importancia en la cultura medieval, que varían desde un vago sentimiento de religiosidad hasta intensas visiones místicas ${ }^{6}$.

La conjunción de música y narrativa obtiene un gran poder emocional. La música puede poner de relieve los más profundos aspectos psicológicos del texto narrativo verbal. Así, por ejemplo, la melodía proporcionaría un contexto emocional al texto; el ritmo musical enfatizaría la energía primaria del relato; el fraseo subra-

francesa como en los Lais de María de Francia, de finales del XII. En el siglo xiv es el término que designa algunos poemas narrativos muy importantes, como el Lay de Sir Orfeo, The Franklin's Tale de los Cuentos de Canterbury de Chaucer, e incluso Sir Gawain y el Caballero Verde, que en su verso 30 se autodenomina «laye».

${ }^{4}$ R. Jakobson, «Linguistics and Poetics», en T. Sевеoк (ed.), Style in Language, Cambridge, MA, MIT Press, 1960, pp. 356-357.

${ }^{5}$ Naturalmente el género poético de la lírica tiene una asociación muy antigua con la música, como nos recuerda no solo la etimología común de «lírica» con «lira», sino el que en inglés la palabra «lyrics» sigue designando la letra de una canción.

"A. Gabrielsson, «Strong experiences with music», en P.N. Juslin y J.A. Sloboda (eds.), Handbook of Music and Emotion. Theory, Research, Applications, Oxford, Oxford University Press, 2011, pp. 560-61 y 563. 
yaría la estructura del propósito o finalidad de la narración; los matices dinámicos o de intensidad musical le darían forma y carácter; la armonía crearía un entorno interactivo, y el contrapunto mostraría la interrelación entre los diversos episodios, personajes o estados de ánimo que se narran ${ }^{7}$. Son aspectos narrativos de la música que tanto los ministriles medievales como los cantantes y músicos de hoy tienen presentes como bases de su arte, ya sea consciente o intuitivamente.

En la Edad Media, concretamente en el ámbito anglo-francés desde finales del siglo XI, cuando la conquista normanda de Inglaterra facilitó esa cultura de fusión, se conocían distintos tipos formales de melodía narrativa: el tono recitativo, que era el más cercano al habla, al rezo y a cierta poesía épica; la melodía de la estrofa laisse, de longitud irregular en decasílabos homófonos y asonantes, asociada con la canción de gesta francesa, que añade musicalidad y variación a la anterior; la del lai, que debía combinar el habla con el canto (los lais líricos probablemente eran parte hablados parte cantados), y, finalmente, el tipo estrófico de melodía narrativa que entronca con la épica germánica, así como con la tradición de baladas populares inglesas y escocesas, que ya son canciones en el sentido más convencional, normalmente repitiendo la misma pauta musical con cada estrofa, así como en el estribillo ${ }^{8}$. Esta última melodía narrativa fue la que perduró con popular vitalidad mucho más allá de la Edad Media, al menos hasta los albores del siglo xx en las baladas tradicionales, y luego en gran medida en la canción popular moderna.

No bien llegado el siglo xx parecía haberse consumado la separación entre narrativa tradicional y melodía, cuya fusión fuera antes tan importante. Es sintomático de la separación de texto y melodía que, cuando el erudito americano Francis James Child se puso a recuperar con el mayor rigor que pudo las baladas tradicionales en su magna colección en cinco tomos The English and Scottish Popular Ballads (18821898), desestimó su dimensión musical y el hecho de que muchas de ellas hubiesen sido recogidas de alguien que las cantaba o de hojas sueltas (broadsheets) donde se especificaba la melodía con la que esperaban ser leídas. Hubieron de pasar muchos años hasta que B.H. Bronson demostró en The Traditional Tunes of the Child Ballads (1959-1972) que las baladas eran textos verbales a la vez que musicales en constante evolución?. Muchas de las baladas recogidas por Child todavía se reconocen como

${ }^{7}$ L. EYERE, «The marriage of music and narrative: explorations in art, therapy, and research». Voices: A World Forum for Music Therapy, vol. 7, núm. 3 (2007), recuperado de http://normt.uib.no/ index.php/voices/article/viewArticle/549/410, y K. Bruscia, Improvisational Models of Music Therapy. Springfield, IL, Charles C. Thomas, 1987, pp. 450-464.

8 J. Stevens, Words and Music in the Middle Ages: Song, Narrative, Dance and Drama, 1050-1350. Cambridge, Cambridge University Press, 1986, pp. 140-143 y 200-203.

${ }^{9}$ En la introducción a un libro suyo posterior, donde explica los resultados de The Traditional Tunes of the Child Ballads, Bronson cita estudios anteriores como el de G.H. Gerould (The Ballad of Tradition, Oxford, Clarendon, 1932, p. 165) y el de Ramón Menéndez Pidal (El Romancero, Madrid, 1927, p. 37) para apoyar su tesis sobre la variación conjunta de música y letra como esencial en «el proceso de poetización comunal»: «It is pertinent to quote here Gerould's remark, that it is 'only by understanding [the processes by which both words and melodies keep continually changing, that] we can find out why ballads and other folk-songs have qualities of their own that are the 
relatos de origen medieval, pero su música había caído en el olvido. En la era de la novela realista, cuando Child realizó su labor recopilatoria, el texto narrativo, incluyendo la poesía y el teatro, tendía a alejarse de la música en los géneros más influyentes (con salvedades como la ópera y las canciones de music hall), hasta que luego llegaron el cine y las canciones de pop y rock a contar sus historias con música. La natural evolución de la música asociada a los relatos medievales, junto con la gradual disyunción entre los temas medievales y la música que un día tuvieron, contribuyeron a que cuando en el siglo xx se quiso evocar musicalmente la Edad Media fue casi siempre con melodías que se imaginaron medievales, o se representaron como tales (asociándolas, por ejemplo, a imágenes también supuestamente medievales), que poco o nada tenían ya del Medievo en términos formales, pero que suscitaban en la mente moderna emociones «típicamente medievales» tales como la nostalgia por un tiempo de armonía perdido, el misticismo, lo macabro o las más crudas pasiones.

\section{DRAMAS SONOROS}

Al tiempo que evolucionaban las formas de asociación entre melodía y narrativa, también lo hizo la conexión entre drama y música. Una de las composiciones musicales más antiguas es el tropo «Quem quaeritis» del drama litúrgico, aunando diálogo y canto. Ethelwold, obispo de Winchester, en unas instrucciones para los monjes benedictinos denominadas Regularis Concordia (c. 965-975), aconseja la adopción para la liturgia pascual de un sencillo drama en dos actos denominados, respectivamente, «Depositio Crucis» y «Elevatio Crucis»: en este último las "Tres Marías» se acercan al sepulcro vacío de Cristo, donde un ángel se dirige a ellas cantando "Quem quaeritis» («¿A quién buscáis...») en un «dulce tono medio» ${ }^{10}$.

result neither of blind chance working upon degenerate strays from an ordinary garden of song, nor a mysterious power somehow resident in the ignorant folk when emotionally stimulated.' He quotes Pidal's insistence that 'variants are not accidents', but rather essentials to the process of communal poetizing». B.H. Bronson, The Singing Tradition of Child's Popular Ballads. Princeton University Press, Princeton, NJ, 1977, p. XLII.

${ }^{10}$ Véase su contexto explicado en D. Hiley, «Plainchant transfigured: Innovation and reformation through the ages», en J. McKinnon (ed.), Man and Music. Antiquity and the Middle Ages, Londres, Macmillan, 1990, pp. 120-142, especialmente en pp. 126-130. El tropo "Quem quaeritis» tuvo una difusión bastante notable, ya que respondía a una política generalizada de subrayar la carga emocional de las celebraciones más importantes del calendario litúrgico mediante el uso de textos dramáticos ańadidos y música cada vez más alejada del canto gregoriano y más próxima a la polifonía. Han sobrevivido textos del mismo tropo en San Marcial de Limoges, Tours, San Galo (Suiza) y en varios manuscritos escandinavos, la mayoría suecos, además del Regularis Concordia de Winchester. Esta última versión aparece traducida del latín al inglés en J. Gassner (ed.), Medieval and Tudor Drama, New York, Applause Book Publishers, 1987 (1963), pp. 37-38, recuperado de http://www3.northern.edu/wild/th100/quem.htm. 
Los tropos se consideran el origen del teatro medieval, y conviene recordar que sus diálogos vienen acompañados de música ${ }^{11}$.

Progresivamente el teatro va dejando los confines de la iglesia, celebrándose primero en las plazas anexas a las catedrales, y luego en carrozas o pasos por las calles de las ciudades, aunque las principales fuentes musicales siguen siendo litúrgicas ${ }^{12}$, de la misma manera que la temática sigue siendo religiosa, sobre todo bíblica. No obstante, los textos dramáticos empiezan a incorporar motivos laicos tradicionales y a veces emplean a ministriles para las partes musicales. Tanto la interpretación de pasajes bíblicos como los acompańamientos musicales se van haciendo cada vez más libres y lúdicos. Uno de los primeros signos de cambio es el drama pascual incluido en el manuscrito Carmina Burana (1220-1230), donde María Magdalena canta en latín y alemán, alaba los goces del mundo y danza provocativamente frente al público. En los dramas ingleses del Corpus Christi celebrados desde el siglo XIV la música ya juega un papel decisivo dentro de la representación, con dos funciones primordiales ${ }^{13}$ : para indicar el carácter de un personaje, desde la música celestial, que evoca a los ángeles y la respuesta humana a lo divino, hasta el carácter diabólico, que llega a expresarse por medio de cacofonías (los diablos aparecen metiendo ruido), y con la función estructural de señalar entradas, salidas, cambios de escena o localización, paso del tiempo y contrastes dramáticos -funciones análogas a las que siglos después tendría la música en el cine-. En algunos episodios de los ciclos teatrales los acompañamientos musicales son decisivos para conseguir efectos dramáticos y emociones. Por ejemplo, en el Secunda Pastorum del Ciclo de Wakefield se establece un contraste entre estilos vocales celestiales y terrenales: tras un episodio picaresco en el que predominan las canciones de raigambre popular, el ángel pone a dormir a los pastores con una música de inspiración religiosa, Gloria in excelsis; al despertar, cantan sus propias canciones (tras un intento fallido de imitar las angélicas) camino de Belén ${ }^{14}$. Lo interesante es ese contraste, apoyado tanto en los textos como en su acompańamiento musical, entre la música entendida como entretenimiento cotidiano en un plano histórico y la música todavía basada en la liturgia, que evoca el plano místico, atemporal.

Geoffrey Chaucer deja patente la estrecha relación entre narrativa, música y teatro en «El Cuento del Molinero» de los Cuentos de Canterbury (ca. 1400). Na-

11 Para ser más exactos, hubo dos formas de enriquecer la liturgia evitando el riesgo teológico implícito en añadir textos demasiado independientes de las Escrituras: los textos llamados "prosulae», que se añadían para cantar en fraseos que antes no los tenían, y el «tropus», que normalmente designaba una frase de canto ańadida, a modo introductorio, antes de las frases melódicas tradicionales. D. Hiley, op. cit., pp. 126-127.

${ }_{12}$ P. Happé, "A guide to criticism of medieval English theatre», en R. Beadle (ed.), The Cambridge Companion to Medieval English Theatre Cambridge, Cambridge University Press, 1994, p. 335 .

${ }_{13}$ De acuerdo con R. Rastall, Minstrels Playing: Music in Early English Religious Drama. Cambridge, D.S. Brewer, 2001, citado por P. HappÉ, op. cit., p. 336.

14 N.C. Carpenter, «Music in the Secunda Pastorum». Speculum, vol. 26 (1951), pp. 696700, y R. Rastall, op. cit., pp. 175-176. 
rrando la historia cómica de un astuto estudiante y un joven clérigo vanidoso que rivalizan por acostarse con la esposa de un viejo carpintero, The Miller's Tale puede entenderse como la plasmación narrativa de una cencerrada (rough music); además, en el cuento, contado por el personaje del molinero que encabeza la compañía de peregrinos a Canterbury tocando la gaita, la música ocupa un lugar muy destacado, trascendiendo la crudeza argumental propia del género al que habitualmente se asigna, el fabliau ${ }^{15}$. El teatro medieval está presente en la trama, puesto que el estudiante Nicholas hace creer al carpintero, muy aficionado al drama y buen conocedor del episodio sobre Noé, que se va a producir un nuevo Diluvio Universal y que debe fabricar un arca donde salvarse junto a su joven esposa Alison. Así el cuento es, en uno de sus planos argumentales, una parodia del misterio teatral conocido como Noah's Flood, culminando con el estruendoso desplome del arca tras una falsa alarma de diluvio. En otro plano el cuento está lleno de alusiones musicales: el estudiante toca el salterio, el clérigo corteja a la esposa con la cítara, y suenan las campanas del presbiterio llamando al canto de laúdes en la madrugada, mientras Nicholas y Alison disfrutan en la cama. Tratándose de un relato, la música, parte de la cultura cotidiana narrada, naturalmente no se oye como tal, sino que se lee y se imagina.

La adaptación de Pier Paolo Pasolini de «El cuento del molinero» recupera el espíritu medieval en buena medida, trayendo al público del cine el ambiente musical de aquella época mediante la banda sonora de Ennio Morricone, la cual en este cuento se basa fundamentalmente en canciones tradicionales inglesas y cantos religiosos en latín (estos últimos los entona el estudiante para infundir solemnidad al engaño que urde cuando profetiza el nuevo diluvio). Al igual que el cuento de Chaucer, la trama de Pasolini culmina teatralmente con la estruendosa cacofonía del arca cuando se derrumba al no tener agua en que flotar. Pero Pasolini pone aún más música en su versión que la fuente en que se basa: sus personajes aparecen cantando muy a menudo (sobre todo en las escenas iniciales), y su efecto general es recrear la vitalidad de la Edad Media por medio de su música, con una devoción al periodo que tiene algo de trascendental en el contexto pasoliniano de la «Trilogía de la Vida».

${ }^{15}$ Sobre la imaginería y el simbolismo de la música en The Miller's Tale, véase D.W. RoberTson, Preface to Chaucer. Princeton, NJ, Princeton University Press, 1963, pp. 127-33, y R. VAldÉs Miyares, «Rough Music: Popular Culture in The Miller's Tale», en A.M. Hornero Corisco y M.P. Navarro Erasti (eds.), Proceedings of the $X^{\text {th }}$ International Conference of the Spanish Society for Medieval English Language and Literature, Zaragoza, Institución "Fernando el Católico», 2000, pp. 267-275.

${ }^{16}$ Las tres películas de Pasolini que conformaron lo que denominó su «Trilogía de la Vida», El Decamerón, Los cuentos de Canterbury (1972) y Las mily una noches (1974), fueron, como apunta el prestigioso crítico Colin MacCabe, un resultado de la obsesión de Pasolini por encontrar un mundo alternativo al mercantilismo capitalista presente: «His obsession was with finding a world outside of all the commodifications of capitalism, including, prominently, the bodily. By grafting the marginal modern (the Italian lumpen poor, the Third World) onto medieval texts, Pasolini hoped to fashion an alternative to a present that he found ever more repellent». C. MACCABE, Perpetual Carnival: Essays on Film and Literature. Oxford, Oxford University Press, 2017, p. 191. Si bien Pasolini estaba exento de religiosidad en un sentido ortodoxo o convencional, su admiración, en este caso, por la Edad Media y su música, sugieren una añoranza de lo trascendente. En palabras de Guillem Català, refiriéndose a 
A finales de la Edad Media las diversas relaciones entre canciones, narración y teatro se van consolidando en aspectos que iban a permanecer constantes, mientras los dramaturgos refinan las funciones de la música en sus tramas. El drama shakesperiano utiliza la música para contribuir al ambiente de fondo, más que a la acción o al argumento ${ }^{17}$. La canción «Under the Greenwood Tree» en Como gustéis (As You Like It) ambienta y celebra un idealizado Bosque de Arden que seguramente debe tanto a la memoria personal del propio Shakespeare (y el recuerdo de su madre, Mary Arden) como a las baladas medievales de Robin Hood $^{18}$, muy populares todavía en su época. Por su parte $A$ Midsummer Night's Dream conjura en forma dramática la musicalidad del mundo de las hadas, e inspiraría poderosamente a compositores posteriores como Felix Mendelssohn y Benjamin Britten cuando quisieron recrear ese mundo ${ }^{19}$. Un mundo de hadas que, con el paso del tiempo, se llegaría a confundir con el mundo medieval.

\section{MINISTRILES Y BALADAS}

Junto con sus orígenes litúrgicos, la música del teatro medieval se nutrió de la tradición popular aportada por los ministriles, que en algunos casos eran empleados por los gremios para escenificar sus misterios teatrales. Del folclore musical también surgió, por otra parte, la balada (cuyo nombre se relaciona con la etimología de ballare, bailar). Desde principios del siglo XVII se evidencia un intercambio entre las baladas que se cantaban en las calles (y se publicaban en pliegos sueltos o broadsides) y las representaciones teatrales: las obras escénicas incorporaban baladas populares, y a veces las canciones escritas para el escenario se convertían en baladas

la utilización de fuentes clásicas de la tradición literaria por parte de Pasolini, «La Tradición implica una vuelta sobre la dimensión transcendente de la Vida. Se entienda como Religión, o no, se crea o no en Dios (o en los Dioses), en todo caso hay un referente mítico. Y una necesidad de dar sentido a nuestras vidas. Nacemos de lo oscuro, con sed de lo sagrado. Si sagrada es la persona, sagrado lo es el mundo. Y blasfema la sociedad, dominada por fuerzas e ideas que niegan la persona. Los placeres del consumo, del furibundo hedonismo de masas, son un trago en el desierto, menos que un salmo en la catedral. La obra de arte debiere ser un recordatorio de esto». G. Català, «Vigencia del Pensamiento de Pasolini» (artículo publicado en la revista Vacio, núm. 6, Barcelona, diciembre 1997 y en El Verdugo, Logroño, núm. 2, verano 1998), recuperado de http://www.academia.edu/11411629/ VIGENCIA_DEL_PENSAMIENTO_DE_PASOLINI_por_Guillem_Catala.

${ }_{17}$ Ese uso de la música limitado a la ambientación es lo que más choca a Lathrop: véase H.B. Lathrop, "Shakespeare's dramatic use of songs". Modern Language Notes, vol. 23 (1 enero 1908), en Shakespeare Online, 20 Aug. 2013 (último párrafo), recuperado de http://www.shakespeare-online. com/plays/hamlet/shakespearesongplays.html.

${ }^{18}$ Sobre la idealización del bosque en las baladas de Robin Hood, véase A.J. Pollard, «A greenwood far away", capítulo 3 de Imagining Robin Hood: The Late Medieval Stories in Historical Context, Londres, Routledge, 2004, pp. 57-81.

19 J. Horvath, «If music be the food of love, play on.' Shakespeare and music II: Midsummer Night's Dream». Interlude, 6 diciembre 2015, recuperado de http://www.interlude.hk/front/ music-food-love-play-shakespeare-music-ii-midsummer-nights-dream/. 
populares $^{20}$. La popular opereta inglesa The Beggar's Opera (John Gay, 1728), cuyo éxito hizo época ${ }^{21}$, está tan basada en las baladas callejeras que definió un nuevo género operístico: la ballad opera. Esa estrecha conexión entre el teatro y la balada se remonta a finales de la Edad Media, cuando Robin Hood parecía ser igual de popular como personaje de teatro que como de balada ${ }^{22}$.

Dada la estrecha conexión entre baladas y música, es lamentable que de muchas de las más famosas, por ejemplo las de Robin Hood, que en origen debieron de asociarse con melodías, no haya sobrevivido música alguna anterior al siglo XVIII. Una de las baladas medievales, Robin Hood y el monje, se inicia describiendo un verde bosque al que nunca llega el invierno, con un texto lírico que es fácil imaginar cantado por un ministril:

In somer, when the shawes be sheyne,

And leves be large and long,

Hit is full mery in feyre foreste

To here the foulys song.

To se the dere draw to the dale,

And leve the hilles hee,

And shadow hem in the leves grene,

Under the grene wode $\operatorname{tre}^{23}$.

Es un bosque fuera del tiempo, emparentado con el Arden de Shakespeare. Aunque algunas de las primeras baladas de Robin Hood, como la que acabamos de citar y $A$ Gest of Robin Hood, no parecen escritas para acompańamiento musical, es probable que esos textos que nos llegaron ya en época de la imprenta fueran narrativizaciones de otras tantas rimas y canciones más antiguas, que perdieron en su mayoría la música y fueron transmitidas exclusivamente como textos narrativos ${ }^{24}$.

${ }^{20}$ J.R. CARR, «An harmless ditte’: Ballad music and its sources», en English Broadside Ballad Archive, recuperado de http://ebba.english.ucsb.edu/page/ballad-music-sources.

${ }_{21}$ The Beggar's Opera gozó de una inmensa popularidad en las Islas Británicas durante el medio siglo siguiente a su estreno. J. BREwer, The Pleasures of the Imagination. English Culture in the Eighteenth Century. Londres, Harper Collins, 1997, pp. 441-445.

${ }_{22}$ El Robin Hood de los espectáculos dramáticos medievales se analiza, por ejemplo, en $\mathrm{S}$. Knight, Robin Hood. A Complete Study of the English Outlaw. Oxford, Blackwell, 1994, pp. 98-114.

23 «En verano, cuando brillan las arboledas, / Y son las hojas espesas y grandes, / Es muy placentero en el bello bosque / Oír el canto de las aves, / Ver a los ciervos acercarse al valle / Y dejar los altos montes, / Y ponerse a la sombra de las hojas verdes, / Bajo el árbol de verde bosque». J.R. Valdés Miyares (ed. y trad.), Baladas de Robin Hood. Madrid, Akal, 2009, pp. 50-51.

${ }^{24}$ En lo que se suele denominar el Texto B del poema alegórico largo Piers Plowman, de William Langland, datado entre 1377 y 1379, aparece un cura holgazán representando al pecado de la Pereza (el cura se llama Sleuthe, Sloth en inglés moderno) que confiesa no saber perfectamente el padrenuestro como lo canta un cura, pero sí las rimas de Robin Hood («I kan noght partitly my Paternoster as the preest it syngeth / But I kan rymes of Robyn Hood...", Passus V, versos 395-396, en A.V.C. Schmidt (ed.), William Langland, The Vision of Piers Plowman. A Complete Edition of 
Muchas baladas serían recogidas a partir del siglo XviII de personas que las conocían cantadas, como Anna Gordon, de quien proceden algunas de las más consagradas baladas tradicionales de Escocia ${ }^{25}$. Pese a que en las baladas que se vendían impresas en hojas sueltas se citaba la melodía con la que había que cantarla -a veces de forma un tanto arbitraria, pues una misma melodía de éxito podía usarse con distintos textos-, la balada tradicional, casi siempre transmitida oralmente, solía estar asociada emocionalmente con una melodía en particular, como pretendió demostrar Bronson ${ }^{26}$ : las historias de expediciones de rapiña o heroicidad a través de la frontera de Escocia, de jóvenes hechizados o hechizadas, de traiciones y venganzas entre clanes, de huidas o de raptos, de amores trágicos y crueles asesinatos por dramas familiares, respondían cada una a su propia música, aunque siempre sujeta a los cambios en la tradición. Las emociones que esas baladas transmitían con su música pervivieron incluso cuando cruzaron el océano y se trasladaron de las Islas Británicas a los Apalaches ${ }^{27}$.

En el plano más estrictamente narrativo algunas baladas entrañan de manera singular una línea de continuidad entre la Edad Media y la época moderna ${ }^{28}$. La balada de "King Orfeo», remontándose a los mitos clásicos y a los lais medievales, llegaría a recogerse cantada de la tradición oral hasta bien entrado el siglo xx, cuando se seguía cantando en las Islas Shetland ${ }^{29}$. Desde su origen en el teatro de Eurípides y los cultos órficos de Alejandría, el tema del mito de Orfeo es el poder sobrenatural de la música para triunfar sobre la muerte. En la Edad Media su versión más popular aparece ligada a la música en dos alusiones francesas a un Lai d'Orphéy cuyo texto no se ha conservado ${ }^{30}$. El rey Orfeo medieval se pierde en el bosque para encontrar el rastro su esposa, hasta que la halla en el mundo de las hadas, de donde, al contrario que el Orfeo clásico, consigue recuperarla gracias a su música, triunfo facilitado

the B-Tex, Londres, Dent, 1987, p. 56. Esto da una idea clara de la popularidad de canciones sobre Robin Hood a finales del siglo xiv.

${ }_{25}$ Véase S. Rieuwerts (ed.), The Ballad Repertoire of Anna Gordon, Mrs Brown of Falkland. Woordbridge, The Boydell Press / The Scottish Text Society, 2011, pp. 66-69.

26 "Although we can never trace a straight linear path for a ballad-tune from generation to generation, [...] the tenacity with which folk-tunes cling to some quintessential core of identity, despite all superficial change of their individual notes, metre, sequence of phrase, is one of the most remarkable facts about them", B.H. BRonson, op. cit., p. xxx.

27 «Ballad emotions», en F. Ritchie y D. OrR, Wayfaring Strangers. The Musical Voyage from Scotland and Ulster to Appalachia. Chapel Hill, The University of North Carolina Press, 2014, p. 34.

28 J.R. VAldÉs Miyares, «Sturdy stories: Medieval narrative into popular ballad». Selim Journal, 12 (2003-2004), 143-159, recuperado de http://digibuo.uniovi.es/dspace/bitstream/10651/27178/1/ Sturdystories.pdf.

${ }^{29}$ B.H. Bronson, op. cit., p. 75, recoge dos melodías distintas de «King Orfeo» cantadas en las Shetland, respectivamente, por John Stickle en 1947 y Kitty Anderson en 1955.

${ }^{30}$ En el Lai de l'Épine (verso 185) y en Floire et Blanceflor (verso 863), citados en M.J. Donovan, The Breton Lay: A Guide to Varieties, Notre Dame, Indiana, University of Notre Dame Press, 1969, p. 147. 
por el hecho de que en estas versiones medievales, profundamente influidas por la mitología celta, Eurídice en realidad no está muerta, sino «tomada» por las hadas ${ }^{31}$.

La pervivencia de ciertas baladas medievales a través de los siglos en la cultura popular, uno de sus atractivos para los escritores románticos, prueba el poder evocativo de las historias que cuentan, a menudo trasladándose a los gustos musicales de diversas épocas. En el siglo xx el mito de Orfeo (que también obtuviera un eco importante en la ópera con autores como Monteverdi en 1607 y Gluck en 1762) llega al cine con fuerza, por ejemplo, en la trilogía de películas órficas de Jean Cocteau, y el Orfeo Negro (1959) del también francés Marcel Camus, basada en una obra teatral del músico brasileño Vinicius de Moraes. En el cine de habla inglesa cabe destacar la película Más allá de los sueños (What Dreams May Come, 1998) del neozelandés Vincent Ward, pero su acento artístico, como ocurre con la Trilogía Órfica de Cocteau, recae mucho más en lo visual que en la música. Además, estas películas se basan en la versión clásica trágica, en la que Orfeo no consigue rescatar a su amada. Es, por tanto, en las baladas inglesas donde el mito órfico permaneció más ligado a la música, como ilustran las diversas versiones que músicos de folk actuales siguen haciendo de "King Orfeo" ${ }^{32}$.

Finalmente, en la medida en que hubo una transición de la narrativa de las baladas a la novela, debemos recalcar que, antes de convertirse en el inventor por excelencia de la novela histórica ${ }^{33}$, Walter Scott fue un ávido coleccionista de baladas escocesas, que publicó, bastante modernizadas y mezcladas con composiciones propias, en una colección en tres tomos entre 1802 y 1803, The Minstrelsy of the Scottish Border. La influencia de las baladas se hace patente en su primera novela histórica (o romance): Waverley (1814), donde buena parte de la inspiración procede de las canciones jacobitas que mitificaban la aventura del último pretendiente Estuardo al trono de Escocia e Inglaterra, el príncipe Carlos Eduardo. En su poema narrativo The Lay of the Last Minstrel (1805), antes de convertirse en novelista, Scott lamenta el fin de la cultura del arpa y los ministriles: el final de una asociación entre la figura de músico y el relato, entre melodía y narración, que pervivió por mucho tiempo en las baladas ${ }^{34}$. La novela, sin embargo, tenía frente al teatro la desventaja de que solo podía utilizar las baladas bien por sus argumentos narrativos o bien por alusión intertextual, sin que su música pudiese oírse más que, si acaso, en la imaginación

31 D. Allen, «Orpheus and Orfeo: The dead and the taken». Medium Aevum, vol. 33, núm. 1 (1964), pp. 102-111. El estudio más completo sobre el Orfeo medieval es de J.B. Friedman, Orpheus in the Middle Ages. Cambridge, MA., Harvard University Press, 1970.

${ }^{32}$ Las principales versiones folk de "King Orfeo" desde 1970 hasta el presente aparecen reseñadas, con sus letras, en https://mainlynorfolk.info/steeleye.span/songs/orfeo.html.

33 En el género de la novela o romance histórico la más ilustre antecesora, y modelo literario, de Walter Scott fue probablemente la autora irlandesa Maria Edgeworth.

${ }^{34}$ El ministril o arpista como héroe o heroína es importante en unas cuantas baladas, además de «King Orfeo», tales como «Fair Annie», «Glasgerion»y «King Estmere». Véase R. VAldés Miyares, "The ballad and the harp...», pp. 361-368, recuperado de https:/www.researchgate.net/ publication/236606238_The_Ballad_and_the_Harp_an_approach_to_the_history_of_English_narrative_song_of_medieval_tradition. 
del lector o lectora conocedores de la misma. El impacto emocional de la música era, por consiguiente, muy indirecto en la novela, ante la ausencia del ministril o cantor de la narración.

\section{MÚSICA NEOMEDIEVAL Y NARRACIÓN FÍLMICA}

En el cine, al contrario que en la novela, la música puede hacerse sentir de las formas más diversas, desde el acompañamiento ambiental y contrapunto narrativo que solo escucha el espectador como música extradiegética hasta su uso diegético, por ejemplo, cuando un personaje canta y comparte el sentido de esa canción con el público. Aunque ya las proyecciones de cine mudo solía acompañarlas un pianista, el cine aprovechó al máximo el poder de la música y las canciones en cuanto se inventó el cine sonoro: no es casualidad que el primer gran éxito del cine sonoro fuese una película musical, El cantor de jazz (The Jazz Singer, 1927), basada en un género de música popular, el blackface minstrelsy, quizás el primer género teatral propiamente americano, y con todo asumiendo la noción de minstrel, de clara resonancia medieval. También el primer gran éxito de Walt Disney Productions en largometrajes de dibujos animados a color, Blancanieves (Snow White and the Seven Dwarfs, 1937), vino acompañado de música, alternando partes habladas con cantadas como acaso lo hicieran los lais medievales. Las canciones eran naturalmente al gusto americano de los años $1930^{35}$, pero recreaban un mundo medieval de castillos, brujas, princesas y enanos procedente de la imaginación medievalista de los hermanos Grimm.

El cine pronto redescubre el bosque de Robin Hood en toda su musicalidad, en cuanto el gran éxito de Douglas Fairbanks en el cine mudo (en Robin Hood, dirigida por Allan Dwan en1922) es superado con creces por el color y el sonido de The Adventures of Robin Hood (Michael Curtiz, 1938). Las historias de Robin Hood, que hacía mucho se habían disociado de la música, renacen con otras melodías en las bandas sonoras musicales. En 1991 una canción del cantautor canadiense Bryan Adams, "(Everything I do) I Do It for You», tema principal del filme Robin Hood, Prince of Thieves (dirigido por Kevin Reynolds), obtuvo un éxito histórico ${ }^{36}$. Era una pieza de rock melódico cuya letra, melodía y estilo, sin embargo, nada tenían que ver con el Robin Hood medieval, salvo en la simbiosis de la figura del héroe proscrito con la música más popular de cada época en que renace.

Para realizar una síntesis del recorrido que hemos realizado desde el teatro y la canción popular de la Edad Media al cine, el punto de encuentro más obvio serían las películas ambientadas en la Edad Media, lo que provocativamente se ha llamado

${ }^{35}$ Las canciones de la película, compuestas por Frank Churchill, Larry Morey y Leigh Hairline, alcanzaron un gran éxito comercial y formaron parte del primer álbum de banda sonora publicado conjuntamente con su largometraje en EE.UU.

36 Por ejemplo, «(Everything I do) I Do It for You» estuvo durante 16 semanas consecutivas en la lista de los singles más vendidos en el Reino Unido, obteniendo el récord de permanencia en dicha lista. Vendió más de 15 millones de discos en todo el mundo. 
el «cine medieval $»^{37}$. El anacronismo de esta frase no es tal cuando se entiende desde la perspectiva crítica más adecuada al tema de la Edad Media en el cine, la del medievalismo. Como autor de El nombre de la rosa, una novela de temática medieval que fue llevada con gran éxito al cine (bajo dirección de Jean Jacques Annaud), Umberto Eco es una referencia clave a la hora de definir el «neo-medievalismo» contemporáneo que reaviva constantemente el interés de la cultura actual por la medieval ${ }^{38}$. El regreso a lo medieval viene teñido de fantasías actuales sobre lo que fue la Edad Media. Por ejemplo, el tema principal de la película Excalibur (John Boorman, 1981) evoca lo medieval por medio de música de Carl Orff de 1936, que a su vez interpreta libremente los poemas y melodías de los Carmina Burana del siglo XIII. En Excalibur la famosa escena de los caballeros en sus brillantes armaduras que recuerdan a los trajes espaciales de películas de ciencia ficción, galopando a cámara lenta como en un wéstern de Sergio Leone, en busca del Santo Grial entre frutales en flor, con la versión musical moderna de Orff del poema goliárdico "O Fortuna», nos recuerda que apenas tenemos acceso a la Edad Media en el cine que no esté mediado por múltiples textos modernos.

Por otro lado, la partitura de James Horner para El nombre de la rosa tiene sus luces y sus sombras ${ }^{39}$ : Horner, especializado en bandas sonoras de ciencia-ficción, compone un score fundamentalmente electrónico, para recrear el ambiente neogótico, de un mundo remoto, muy alejado del nuestro. La música del cine medieval tiende a conjurar una época misteriosamente distante, legendaria, con un sentido de anhelo y nostalgia ${ }^{40}$. Otro buen ejemplo es la música new age de Enya para $E l$ señor de los anillos: la comunidad del anillo (2002), concretamente la canción «May

${ }^{37}$ El cine «medieval» como paradoja lo discuten brevemente, por ejemplo, L.T. RAMEY, y T. Pugh, Race, Class and Gender in «Medieval» Cinema. Nueva York, Palgrave Macmillan, 2007, pp. 1-8.

${ }^{38}$ U. Eco, «Dreaming in the Middle Ages», en Travels in Hyperreality, transl. by W. Weaver, Nueva York, Harcourt Brace, 1986, 61-72: en este influyente artículo, Eco define el nuevo interés en la Edad Media como una curiosa oscilación entre el neomedievalismo fantástico y el estudio filológico más riguroso del periodo. En otros escritos Eco describe la época contemporánea como un regreso a la cultura medieval en diversos aspectos, tales como los escenarios apocalípticos de crisis, el «neonomadismo» y "los errantes», la inseguridad política, la preocupación por la autoridad, ciertas formas de pensamiento binario, el arte como bricolaje o el «monasticismo» de ciertos campus universitarios: U. Eco, «Hacia una nueva Edad Media», en La estrategia de la ilusión, trad. de Edgardo Oviedo, Barcelona, Editorial Lumen, 1986, pp. 87-113. Véase también U. Eco, F. Colombo, F. Alberoni, y G. SACCo, La nueva Edad Media. Madrid, Alianza Editorial, 1997. Para situar los «medievalismos» en un contexto más amplio, véase R. SAN Martín BAstida, «De Edad Media y Medievalismos: Propuestas y Perspectivas». Dicenda. Cuadernos de Filología Hispánica, vol. 22 (2004), pp. 229-247, recuperado de https://revistas.ucm.es/index.php/DICE/article/view/DICE0404110229A29A/12121. El medievalismo como proceso mitificador y origen de mitos lo explica M.B. Hernández PÉrez, «La Edad Media: forja de mitos, forja de un mito", en C. Rodríguez González y R. VAldés Miyares (eds.), Historia y representación en la cultura global, Oviedo, KRK, 2008, pp. 183-192.

${ }_{39}$ Véase, por ejemplo, la breve reseña de Pablo Nieto para la revista en línea Score Magazine, recuperada de http://www.scoremagacine.com/Resenas_det.php?Codigo=131\&letra=N.

${ }^{40} \mathrm{H}$. DeLL, "Yearning for the sweet beckoning sound': Musical longings and the unsayable in medievalist fantasy fiction». Postmedieval: A Journal of Medieval Cultural Studies, vol. 2 (2011), pp. 171-185. 
It Be», que, al igual que sucede con la música de Excalibury de El nombre de la rosa, no pretende recuperar la música de la Edad Media, sino el imaginario musical que tenemos en nuestra época sobre lo que sería aquella otra época.

En ocasiones el medievalismo musical adopta en el cine formas que aparentemente nada tienen que ver con la Edad Media, sino más bien con ese sentimiento de nostalgia por un mundo ideal perdido que a menudo consideramos medieval. Así, hay algo de medieval en el uso de canciones antiguas para evocar el pasado, incluso si esa antigüedad se limita a una década, como cuando George Lucas vuelve la vista a la cultura de su adolescencia en American Graffiti (1973) a través de una banda sonora que recopila las canciones de la era de finales de los 1950 a principios de los 60, una época llena de nostalgia por la supuesta inocencia perdida tras sucesos como los asesinatos de Kennedy y Luther King, antes de la guerra del Vietnam. Probablemente no sea una coincidencia que tras esa película Lucas concentrara sus esfuerzos creativos en la caballería futurista, neomedieval, de La guerra de las galaxias. Era parte de lo que se ha denominado una política de nostalgia en el cine de Hollywood por el mundo del rey Arturo y la Tabla Redonda ${ }^{41}$. La ambientación medieval por medio de oldie goldies, es decir, canciones modernas que se consideran clásicas, es otra forma de nostalgia medievalista ${ }^{42}$. A Knight's Tale (Destino de caballero), de Brian Hengeland (2001), abre el nuevo siglo con una audaz recreación de la época de Chaucer (el poeta inglés del siglo XIV incluso aparece como personaje) acompañada de clásicos del rock y el pop como «We Will Rock You» de Queen, coreado por los espectadores de un torneo como si se tratase de un partido de fútbol, o "Golden Years» de David Bowie bailado en un baile de corte medieval que recuerda a una discoteca. Como decía Eco al explicar su medievalismo posmoderno cuando escribió El nombre de la rosa, "puesto que el pasado no puede destruirse -su destrucción conduce al silencio- lo que hay que hacer es volver a visitarlo; con ironía, sin ingenuidad ${ }^{43}$. El cine ya no precisa fingir o pretender que la música con que evoca la Edad Media es realmente medieval.

\section{CONCLUSIÓN: MÚSICA IN ILLO TEMPORE}

Nos interesa aquí, finalmente, recalcar la pervivencia en la cultura actual de una profunda asociación entre lo medieval y la música. Dado que, como veíamos en las primeras secciones de este artículo, el Medievo se caracterizó por aunar música y

${ }^{41}$ S. Aronstein, Hollywood Knights: Arthurian Cinema and the Politics of Nostalgia. Houndmills, Palgrave Macmillan, 2005, pp. 106-118.

${ }^{42}$ El medievalismo implícito en American Graffiti y otras películas norteamericanas que incorporan canciones de rock antiguas lo analizo en R.V. VALDÉs MiYARES, "The meaning of romance': popular song and historical narrative from Arthurian literature to American Graffiti». Journal of Film Music, vol. 7, núm. 1 (2017), en prensa.

43 U. Eco, Apostillas a "El nombre de la rosa». Trad. Ricardo Pochtar, Barcelona, Editorial Lumen, 1985, p. 74. 
narración, tan importante como contar sus historias es recrearlo musicalmente, por los medios que tenemos a nuestro alcance, incluyendo videojuegos cuya música neomedievalista intenta reavivar ese mundo imaginario en toda su sonora emoción ${ }^{44}$. La misma función la tiene en la serie televisiva Juego de tronos, que, tal como sugieren las imágenes digitales del mapa medieval ficticio de la serie en sus créditos iniciales, narrativamente también puede relacionarse con los videojuegos.

Hoy en día el mundo medieval aparece expresado musicalmente por dos medios fundamentales, cuya popularidad excede los loables esfuerzos por recuperar y conservar la música antigua en entornos académicos o para minoritarios públicos selectos: uno son las bandas sonoras de películas y videojuegos, y otro son las canciones folk basadas en canciones medievales, álbumes conceptuales y estilos de rock como el llamado «medieval metal», todos los cuales, en formas musicales muy diversas, se inspiran en la Edad Media ${ }^{45}$.

Los relatos medievales de nuestro tiempo ya poco tienen que ver narrativa o musicalmente con la Edad Media: son más bien recreaciones neomedievales de un mundo imaginario. Pese a ello, la música sigue desempeñando una función comparable a la música del teatro medieval y la de las baladas, en subrayar el ambiente y sobre todo las emociones que sustenta la parte argumental narrativa. Al dar una forma al tiempo distinta a la del tiempo cronológico, verbal de la narración (tiempos verbales, adverbios circunstanciales...), la música (tempo, cadencia, ritmo, compás...) que acompaña al relato tiende a establecer una dialéctica con ese tiempo narrativo, aludiendo a otro tiempo cargado de emociones musicales. Una función característica de la música en el teatro medieval era evocar la harmonía del cielo; en el teatro de Shakespeare, el mundo pastoral y de las hadas, y en el cine medieval, ese -por decirlo con la expresión utilizada por Mircea Eliade para designar el tiempo en la narración mitológica- in illo tempore ${ }^{46}$ : un tiempo mítico, a veces idílico, más a menudo salvaje o cruel, de pasiones primarias, pero siempre fascinante de imaginar, que es el Medievo hoy.

RECIBIDO: enero 2017, ACEPTADO: junio 2017

${ }^{44}$ Por ejemplo, la música del videojuego Tzar: The Burden of the Crown (2000), de la empresa búlgara Haemimont Games.

${ }_{45}$ Un buen ejemplo de un álbum de heavy metal conceptualmente medieval es Dance of Death, de Iron Maiden (2003). El «medieval metal», por otra parte, es un término asignado a bandas que, a diferencia de Iron Maiden, se especializan en sonidos supuestamente medievales, sobre todo bandas alemanas como Corvus Corax, In Extremo, Tazwut, Outlaws of Ravenhurst, o la americana Obsequiae.

${ }^{46}$ M. Eliade, El mito del eterno retorno. Trad. de Ricardo Anaya, Buenos Aires, Emecé, 2001, define illud tempus como la Edad de Oro o tiempo sagrado, cuando el ritual que da sentido normativo a una sociedad fue llevado a cabo por primera vez por un dios, antepasado o héroe (pp. 10, 17, 22, 65 y 71), un tiempo hacia el que las civilizaciones tienden en un regreso continuo al acto cosmogónico original (p. 52). Hay en el pensamiento contemporáneo una especie de «eterno retorno» al mito (de lo) medieval, tal como sugiere M.B. Hernández Pérez, op. cit., p. 186. 


\section{BIBLIOGRAFÍA}

Allen, Dorena, "Orpheus and Orfeo: The dead and the taken». Medium Aevum, vol. 33, núm. 1 (1964), pp. 102-111.

Aronstein, Susan, Hollywood Knights: Arthurian Cinema and the Politics of Nostalgia. Houndmills, Palgrave Macmillan, 2005.

Beadle, Richard (ed.), The Cambridge Companion to Medieval English Theatre. Cambridge, Cambridge University Press, 1994.

Brewer, John, The Pleasures of the Imagination. English Culture in the Eighteenth Century. Londres, Harper Collins, 1997.

Bronson, Bertrand Harris (ed.), The Singing Tradition of Child's Popular Ballads. Princeton, Princeton University Press, NJ, 1977.

Bruscia, Kenneth E., Improvisational Models of Music Therapy. Springfield, IL, Charles C. Thomas, 1987.

Carpenter, Nan Cooke, «Music in the Secunda Pastorum». Speculum, vol. 26 (1951), pp. 696-700.

CARr, J.R., "An harmless ditte': Ballad music and its sources». English Broadside Ballad Archive, http://ebba.english.ucsb.edu/page/ballad-music-sources.

Dell, Helen. «Yearning for the sweet beckoning sound': Musical longings and the unsayable in medievalist fantasy fiction». Postmedieval: A Journal of Medieval Cultural Studies, vol. 2 (2011), pp. 171-185. http://dx.doi.org/10.1057/pmed.2011.3.

Donovan, Mortimer J., The Breton Lay: A Guide to Varieties. Notre Dame, Indiana, University of Notre Dame Press, 1969.

Eco, Umberto, Apostillas a «El nombre de la rosa». Trad. de Ricardo Pochtar, Barcelona, Editorial Lumen, 1985.

Eco, Umberto, "Hacia una nueva Edad Media», en La estrategia de la ilusión. Trad. de Edgardo Oviedo, Barcelona, Editorial Lumen, 1986, pp. 87-113.

Eco, Umberto, Furio Colombo, Francesco Alberoni y Giuseppe Sacco, La nueva Edad Media. Madrid, Alianza Editorial, 1997.

Elíade, Mircea, Le Mythe de l'éternel retour. París, Gallimard, 1969. El mito del eterno retorno. Trad. de Ricardo Anaya, Buenos Aires, Emecé, 2001.

Eyere, Lillian, "The marriage of music and narrative: explorations in art, therapy, and research». Voices: A World Forum for Music Therapy, vol. 7, núm. 3 (2007), recuperado de http://normt. uib.no/index.php/voices/article/viewArticle/549/410.

Friedman, John Block, Orpheus in the Middle Ages. Cambridge, MA., Harvard University Press, 1970.

Gabrielsson, Alf, «Strong experiences with music», en Patrik N. Juslin y John A. Slodoba (eds.), Handbook of Music and Emotion. Theory, Research, Applications, Oxford, Oxford University Press, 2011, pp. 547-574.

Hernández Pérez, M. ${ }^{a}$ Beatriz, «La Edad Media: forja de mitos, forja de un mito», en Carla Rodríguez González y Rubén Valdés Miyares (eds.), Historia y representación en la cultura global, Oviedo, KRK, 2008, pp. 183-192.

Horvath, Janet, "If music be the food of love, play on.' Shakespeare and music II: Midsummer Night's Dream». Interlude, 6 diciembre 2015, recuperado de http://www.interlude.hk/front/ music-food-love-play-shakespeare-music-ii-midsummer-nights-dream/. 
Jakobson, Roman, «Linguistics and poetics», en T. Sebeok (ed.), Style in Language. Cambridge, MA, M.I.T. Press, 1960 , pp. 350-377.

Juslin, Patrik N. y John A. Slodoba, (eds.), Handbook of Music and Emotion. Theory, Research, Applications. Oxford, Oxford University Press, 2011.

Knight, Stephen, Robin Hood. A Complete Study of the English Outlaw. Oxford, Blackwell, 1994.

Lathrop, H.B. «Shakespeare’s dramatic use of songs». Modern Language Notes, vol. 23, 1 enero 1908. Recuperado de Shakespeare Online, 20 agosto 2013, http://www.shakespeare-online.com/ plays/hamlet/shakespearesongplays.html.

MacCabe, Colin, «Pasolini's Trilogy of Life», en Perpetual Carnival: Essays on Film and Literature, Oxford, Oxford University Press, 2017, pp. 190-197.

McKinnon, James (ed.), Man and Music. Antiquity and the Middle Ages. Londres, Macmillan, 1990.

Pollard, A.J., Imagining Robin Hood: The Late Medieval Stories in Historical Context. Londres, Routledge, 2004.

Ramey, Lynn T. y T. Pugh, Race, Class and Gender in "Medieval» Cinema. Nueva York, Palgrave Macmillan, 2007.

Rastall, Richard, Minstrels Playing: Music in Early English Religious Drama. Cambridge, D.S. Brewer, 2001.

Rieuwerts, Sigrid (ed.), The Ballad Repertoire of Anna Gordon, Mrs Brown of Falkland. Woordbridge, The Boydell Press / The Scottish Text Society, 2011.

Ritchie, Fionna y Doug OrR, Wayfaring Strangers. The Musical Voyage from Scotland and Ulster to Appalachia. Chapel Hill, The University of North Carolina Press, 2014.

San Martín Bastida, Rebeca, «De Edad Media y Medievalismos: Propuestas y Perspectivas». Dicenda. Cuadernos de Filología Hispánica, vol. 22 (2004), pp. 229-247, recuperado de https:// revistas.ucm.es/index.php/DICE/article/view/DICE0404110229A29A/12121.

Stevens, John, Words and Music in the Middle Ages: Song, Narrative, Dance and Drama, 1050-1350. Cambridge, Cambridge University Press, 1986.

VAldÉs Miyares, J. Rubén, «The ballad and the harp: An approach to the history of English narrative song of medieval tradition», en M.P. Fernández Nistal y J.M. Bravo Gozalo (eds.), Proceedings of the $V I^{\text {th }}$ International Conference of the Spanish Society for Medieval English Language and Literature, Valladolid, Secretariado de Publicaciones de la Universidad, 1995, pp. 361-368.

Valdés Miyares, J. Rubén, «Rough music: Popular culture in The Miller's Tale», en A.M. Hornero Corisco y M.P. Navarro Erasti (eds.), Proceedings of the $X^{\text {th }}$ International Conference of the Spanish Society for Medieval English Language and Literature, Zaragoza, Institución Fernando el Católico, 2000, pp. 267-275.

Valdés Miyares, J. Rubén, «Sturdy stories: Medieval narrative into popular ballad». Selim Journal, 12 (2003-2004), 143-159, recuperado de http://digibuo.uniovi.es/dspace/bitstream/10651/27178/1/ Sturdystories.pdf.

Valdés Miyares, J. Rubén (ed. y trad.), Baladas de Robin Hood. Madrid, Akal, 2009.

VAldÉs MiYares, J. Rubén, "The meaning of romance’: popular song and historical narrative from Arthurian literature to American Graffiti». Journal of Film Music, vol. 7, núm. 1 (2017), en prensa. 
